\title{
REVIEW
}

\section{The Response of Liver Macrophages to Inflammatory Stimulation}

\author{
Karl Decker \\ Institute of Biochemistry and Molecular Biology, Albert-Ludwig University, Freiburg, Germany
}

(Received for publication on October 24, 1997)

\begin{abstract}
The gut is the major source of inflammatory agents that affect the liver. Of these compounds, the endotoxins are the most frequent and best studied intruders. The resident macrophages of the liver, the Kupffer cells, are among the first to respond to this complex. Following contact with the cluster of differentiation (CD) 14 protein, the complex triggers a signal cascade involving the nuclear factor $\mathrm{kB}$. This factor enhances the expression of inflammation-related genes, e.g. those encoding cytokines. Tumor necrosis factor- $\alpha$ is responsible for nearly all of the effects ascribed to endotoxins (lipopolysaccharides). Interleukin (IL)-6, also a product of lipopolysaccharide-activated Kupffer cells, may be instrumental in eliciting the acute-phase response of hepatocytes, while transforming growth factor- $\beta$ promotes conversion of quiescent hepatic stellate cells into a collagen-producing myofibroblast-like form. A different signal pathway triggered by bound endotoxin involves a mitogenactivated protein kinase and leads to the activation of phospholipase $A_{2}$ and the synthesis of the eicosanoids. Endotoxin also induces a nitric oxide synthase in Kupffer cells. This inorganic mediator may participate in the relaxation of the hepatic sinusoid, but may also, together with macrophage-derived superoxide, produce strong oxidants. Tumor necrosis factor- $a$ and nitric oxide play a significant role during liver regeneration after partial hepatectomy. Of the various effects of eicosanoids, their regulatory role in cytokine production by Kupffer cells may be the most important. The regulation of Kupffer cell functions by cell volume change has very recently become apparent. (Keio J Med 47 (1): 1-9, March 1998)
\end{abstract}

Key words: Kupffer cells, lipopolysaccharide, nitric oxide, prostaglandin $E_{2}$, tumor necrosis factor- $\alpha$

\section{Liver Macrophages: A First-line Defense against Endotoxin}

Many compounds that elicit inflammatory reactions enter the systemic circulation via the portal vein. Lipopolysaccharides (LPS), components of the outer membrane of Gram-negative intestinal bacteria, are the most frequent intruders. Also referred to as endotoxin, these high-molecular weight compounds may enter from the gut as part of intact bacteria or in free form as their degradation products. Tiny amounts of LPS penetrate the intestinal wall at all times. However, various pathological conditions lead to leakage of the intestinal barrier and allow larger amounts of LPS to reach the portal blood. Severe inflammatory reactions including endo- toxic shock are the result of endotoxinemia.

The resident macrophages of the liver sinusoids, the Kupffer cells, are among the first cells to encounter these invaders. They are able to bind, internalize and degrade most of the incoming LPS. ${ }^{1}$ Binding is accomplished by the CD14 complex in the macrophage plasma membrane with the aid of an LPS-binding protein. ${ }^{2}$ It appears, however, that CD14-independent mechanisms of uptake are also available. ${ }^{3}$ It has recently been shown that LPS itself triggers the expression of CD14, ${ }^{4}$ such that an autostimulated phase of uptake would be expected. The kinetics of the cellular response are compatible with this notion.

The complex between the LPS-binding protein (LBP), the membrane-associated CD14 and LPS trig-

Presented at the 1014th Meeting of The Keio Medical Society in Tokyo, March 19, 1997.

Reprint requests to: Dr. Karl Decker, Institute of Biochemistry and Molecular Biology, Albert-Ludwig University, Hermann-Herder-Str. 7 D-79104 Freiburg i.Br., Germany 
gers a signal transduction cascade that results in the synthesis and release of a wide spectrum of mediators; these signal molecules may be peptides (interleukins (IL) $-1 \beta,-6,-10$, tumor necrosis factor- $\alpha$ (TNF- $\alpha$ ), transforming growth factor (TGF- $\alpha / \beta)$, interferon- $\alpha / \beta$, lipids (eicosanoids, platelet-activating factor) or inorganic radicals (superoxide, nitric oxide).

\section{Transduction of Inflammatory Signals}

Cytokine synthesis by macrophages can be elicited not only by LPS but also by many other agents including TNF- $\alpha$, IL-1 $\beta$, and several metabolic stress factors. A prerequisite for their activity is the presence of a receptor on the plasma membrane; after binding of the effector molecule, the intracellular domain of the receptor must connect to a signal transduction cascade. The best studied example is that triggered by TNF- $\alpha-\mathrm{TNF}$ receptor-1 although the pathophysiological importance of the autostimulation of macrophages with TNF- $\alpha$ has not yet been established. It may be relevant for the proliferative or the apoptotic effects typical of TNF- $\alpha$ rather than for the response to inflammatory agents. Different receptors connect to different proteins in the primary steps of the cascade. Apparently, however, they all converge in the use of the transcription factor nuclear factor $\kappa \mathrm{B}(\mathrm{NF}-\kappa \mathrm{B}) / \mathrm{Rel}$. NF- $\kappa \mathrm{B}$ is a heterodimeric protein consisting of a 50 and a $65 \mathrm{kDa}$ subunit $^{5}$. In some cells, this transcription factor is present and active in the nucleus without specific stimulation. In most instances, however, NF-kB resides in the cytosol bound to an inhibitor of $\mathrm{NF}-\kappa \mathrm{B}, \mathrm{I}_{\mathrm{K}} \mathrm{B}^{6}$ that prevents its transit to the nucleus.

Activation of the signal transduction cascade elicited by an inflammatory agent leads to the release of NF- $\kappa B$ from its complex with the inhibitor ${ }^{7}$ (Fig 1). In this process, the inhibitor is phosphorylated by an IKBkinase that itself is activated following contact of the eliciting signal with the macrophage. The phosphorylated I $\mathrm{B}$ binds to ubiquitin and is proteolytically cleaved by

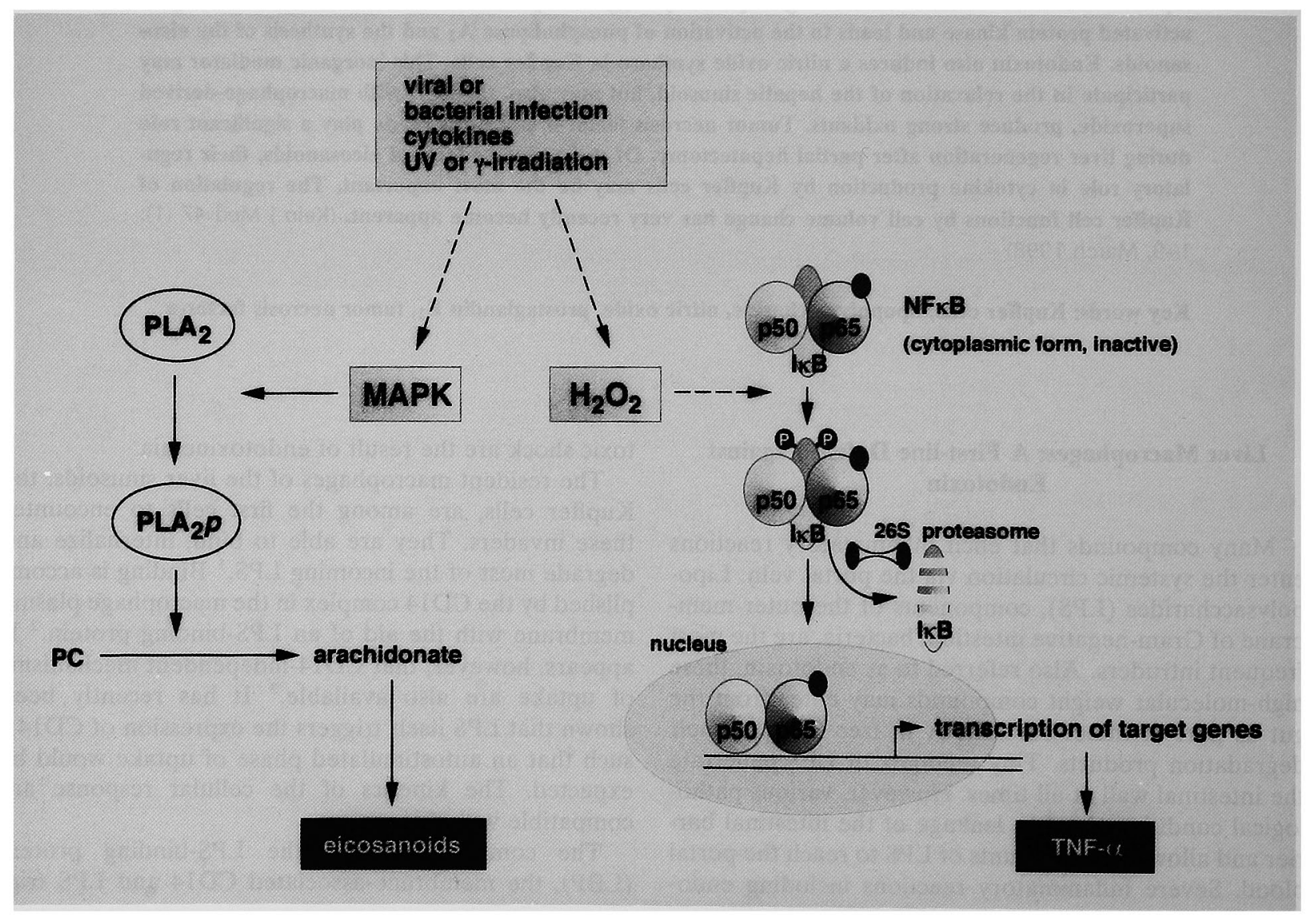

Fig 1 Simplified scheme of the transduction of inflammatory signals involving NF-kB. The MAP-kinase pathway involved in eicosanoid synthesis is also shown. 
the cytosolic proteasome complex. The liberated NF- $\mathrm{kB}$ is able to travel to specific binding motifs in the nuclear DNA and elicit the expression of specific proteins. The signal cascade leading from LPS/CD14 to NF-kB activation is not yet fully understood, but reactive oxygen intermediates (ROI), most likely hydrogen peroxide, are considered essential for this process. ${ }^{8}$ The intracellular source of hydrogen peroxide is not known, but its formation through a short-cut in the respiratory chain is a likely source. Remarkably, LPS-activation of NF- $\mathrm{kB}$ is inhibited by various cytokines ${ }^{9}$ (Fig 2).

Another nuclear factor, AP-1 (Jun/Fos), appears to be inversely regulated. Agents, such as phagocytosable particles, that elicit the formation of oxygen radicals rather than cytokine synthesis, activate AP-1 but inhibit $\mathrm{NF}-\mathrm{kB}$ activation. This is in line with the observation that liver macrophages exposed to phagocytotic stimulation alone do not produce cytokines while inflammatory agents such as LPS and certain viruses do not by themselves trigger superoxide release although they do potentiate the effect of a concomitant phagocytosis.

A different signal transduction pathway leads from the LPS/LBP/CD14 complex to the biologically active arachidonate derivatives, the eicosanoids. It appears to involve a mitogen-activated protein (MAP) kinase that leads to the phosphorylation of phospholipase $\mathrm{A}_{2}$; this enzyme liberates arachidonic acid from phospholipids.

\section{Hepatic Inflammatory Mediators}

TNF- $\alpha$ appears to be the most important inflammatory mediator. When given systemically, it produces all the symptoms of endotoxinemia. However, experiments using antibodies against and soluble receptors for TNF- $\alpha$ or TNF $^{10}$ and TNF receptor knockout animals, ${ }^{11}$ respectively, indicate that the functions of TNF- $\alpha$ can partially be taken over by other mediators, mainly by IL- $1 \beta$. In the liver, TNF- $\alpha$ is exclusively synthesized by Kupffer cells and, surprisingly, also by canalicular epithelial cells. The liver macrophages are also the source of other mediators (Table 1), e.g. IL-1 $\beta$ and IL-6, although other non-parenchymal cells of the liver, particularly the sinusoidal endothelial cells, have also been shown to produce some of these interleukins.

The function of IL- 6 is of particular interest. This cytokine plays a prominent role in the liver as a coelicitor of the "actue phase reaction". In a severe stress situation, e.g. inflammation, glucocorticoid hormones will induce the expression of the IL-6 receptor in hepatocytes. ${ }^{12}$ IL- 6 released from LPS- or virus-stimulated Kupffer cells ${ }^{13}$ will bind to this receptor and trigger the synthesis of "acute phase proteins". These proteins are transported into the blood and serve as protease inhibitors or transporters. While the number of IL- 6 receptors on hepatocytes is normally low, there is an

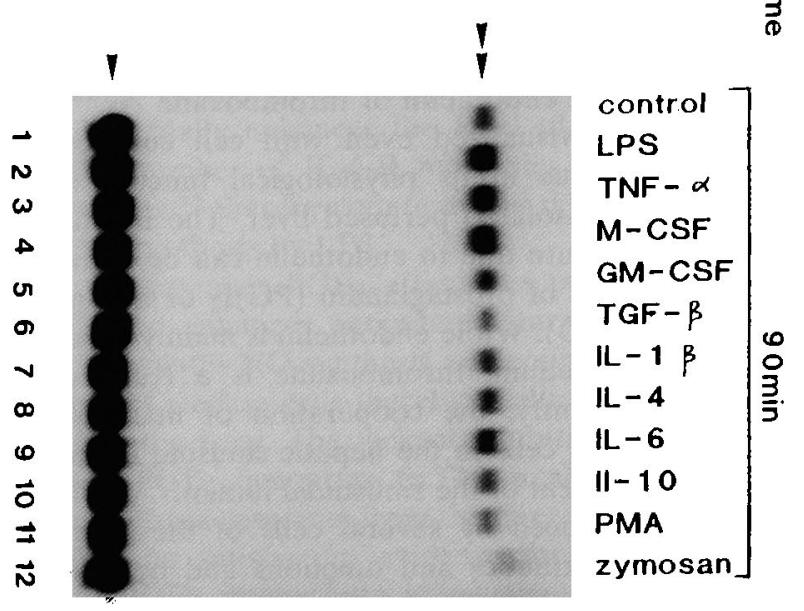

Fig 2 Effectors of NF-kB activity in LPS-treated rat kupffer cells. Gel shift assay (GEMSA) using a total cell extract and labelled oligonucleotide with a binding site for NF-kB. ${ }^{9}$

Table 1 Signals Released by Non-parenchymal Rat Liver Cells

Endothelial Cells:

Endothelin, IL-1, IL-6, NO, PGI 2

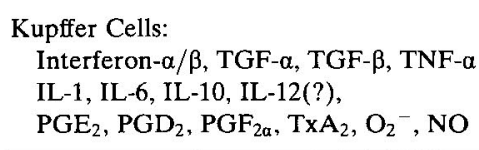

Stellate Cells:

a. fibroblast growth factor, hepatocyte growth factor, TGF- $\beta$, $\mathrm{PGE}_{2}, \mathrm{PGD}_{2}, \mathrm{PGF}_{2 \alpha}$

Pit Cells (large granular lymphocytes):

Interferon- $\gamma$, IL-1 (?)

Mast Cells:

Leukotriene $\mathrm{C}_{4}$, histamine

enormous increase after exposure to IL-6, especially in the presence of glucocorticoids that are released from the adrenals under conditions of stress. In this capacity, IL-6 may be seen as an anti-inflammatory agent. Although blood monocytes produce much more IL-6 per cell than do Kupffer cells, the topographical proximity of liver macrophages to hepatocytes and the fact that the body contains greater numbers of Kupffer cells than monocytes underscore the importance of Kupffer cell-derived IL- 6 for the acute phase reaction.

Another cytokine released from activated Kupffer cells is transforming growth factor (TGF)- $\beta$. Its main function in the liver seems to be the transformation of 
hepatic stellate cells (also known as Ito cells, fat-storing cells, or perisinusoidal lipocytes) into myofibroblastlike cells. In this state, they become contractile under the influence of endothelin or thromboxane $\mathrm{A}_{2} \cdot{ }^{14}$ This effect can be visualized even with cell cultures but becomes obvious in its physiological function when elicited in the isolated perfused liver. The increase in perfusion pressure due to endothelin can be alleviated by the addition of prostaglandin $(\mathrm{PG}) \mathrm{I}_{2}$ or a donor of nitric oxide (NO). While endothelin is mainly produced by the endothelium, thromboxane is a Kupffer cell product. Evidently, the cooperation of macrophages and endothelial cells in the hepatic sinusoid is optimal for the adjustment of the sinusoidal lumen.

NO is produced by several cells of the liver, but with different kinetics and functions and by different enzymes. The constitutive NO synthase is present in hepatocytes and endothelial cells; it is stimulated by agents like acetyl choline or bradykinin. The Kupffer cells contain an inducible NO synthase; its synthesis is induced most forcefully by interferon $-\gamma$, but inflammatory stimuli like LPS or TNF- $\alpha$ are also good elicitors of its expression. ${ }^{15}$ The induction by LPS or TNF- $\alpha$ is strongly enhanced in the presence of $\mathrm{PGE}_{2}$. cAMP can replace $\mathrm{PGE}_{2}$ in the LPS-mediated NO synthesis.

NO serves a dual function in the mammalian organism: it lowers the tension of blood vessels (or sinusoids), but it may also become a strongly cytotoxic oxidant. Since the compound is the same in both instances, it must be the environment and the cell type involved that makes the difference. NO possesses a high affinity for complexed iron; thus, it is an inhibitor of enzymes whose activity depends on iron complexes and that are easily accessible to NO. One of these is the guanylate cyclase that produces cGMP; this enzyme is thought to be the target of the dilatory effect of NO in smooth muscle or myofibroblast-like cells.

The cytotoxic effect of NO cannot be fully explained by this mechanism. It is presently thought that NO must be converted to a more reactive derivative. The partner suited best for this reaction is superoxide $\left(\mathrm{O}_{2}{ }^{-}\right)$; together with $\mathrm{NO}$ it produces highly reactive compounds such as peroxynitrite that are able to destroy organic matter. ${ }^{16}$

$\mathrm{O}_{2}{ }^{-}$is a typical product of macrophages. A membranespanning NADPH oxidase binds NADPH on the cytoplasmic side and uses an electron to reduce in the periplasmic space one molecule of molecular oxygen (dioxygen) to superoxide. Kupffer cells produce it whenever they come in contact with a phagocytosable particle such as a bacterium, a dying erythrocyte or an immune complex. It appears that the binding scavenger receptor or some other more specific receptor produces a signal that ultimately results in the activation and assembly of the NADPH oxidase in the plasma mem- brane. The binding of a particle leads to the involution of the respective "bristle-coated" clathrin-connected membrane area with formation of phagosomes; thus, the major part of the superoxide produced is released into this closed space ${ }^{17}$ and can reach significant concentrations. If at the same time NO is fed in - be it from the Kupffer cells themselves or from stimulated sinusoidal endothelial cells - the conditions for peroxynitrite formation and oxidative destruction of the particle are created.

\section{NO and TNF- $\alpha$ in Liver Regeneration}

During the prereplicative period of liver regeneration, the changes of the messenger RNA (mRNA) contents for TNF- $\alpha$ and its receptors are nearly synchronous. The mRNA levels reach their maximum at $1-3 \mathrm{~h}$ after operation and exceed the respective values in intact animals by about ten-fold. LPS stimulation induces an increase in TNF- $\alpha$ and TNF receptor production comparable to that during regeneration. ${ }^{18}$

NO production in the regenerating liver, ${ }^{19}$ as determined by electron paramagnetic resonance spectroscopy, starts to increase approximately $1 \mathrm{~h}$ after partial hepatectomy (PHE). A second and more pronounced NO production peak occurs about $6 \mathrm{~h}$ after PHE when the hepatocytes enter the first cell cycle. This NO originates mainly within the parenchymal cells. The following minimum of NO synthesis coincides with the maximal rate of DNA synthesis. A third gradual rise of NO production occurs at the transit from the first to the second cell cycle of the hepatocytes and the entrance of the nonparenchymal cells into proliferation.

Hepatocytes, Kupffer and endothelial cells isolated from livers after PHE revealed that each cell type starts its major NO production at the time corresponding to its respective entrance into the cell cycle. ${ }^{20}$ The maxima of NO synthesis seem to be inversely correlated to the DNA-synthesizing activity of the individual cell type supporting the notion that $\mathrm{NO}$ is involved in the regulation of the cell cycle.

\section{Eicosanoids and Platelet Activating Factor}

Eicosanoids comprise the bioactive derivatives of the highly unsaturated, 20-carbon arachidonic acid. They include the prostaglandins, prostacyclin, thromboxane and the leukotrienes. In rat liver, prostaglandins are synthesized mainly by stimulated Kupffer cells, but elicited sinusoidal endothelial and hepatic stellate cells are also releasing some of these agents. Hepatocytes, on the contrary, do not produce eicosanoids, but they are the major site where their degradation takes place. ${ }^{21}$ Inflammatory agents such as LPS or some cytokines elicit the release of $\mathrm{PGE}_{2}, \mathrm{PGD}_{2}$ and thromboxane $\mathrm{A}_{2}$ 
$\left(T x A_{2}\right)$ (for review $s^{22}$ ). The effect of TNF- $\alpha$ is mediated by the $55 \mathrm{kDa}$ TNF- $\alpha$ receptor; anti-TNF- $\alpha$ receptor antibody is able to elicit $\mathrm{PGE}_{2}$ production by rat Kupffer cells. While a $\mathrm{Ca}^{2+}$-dependent phospholipase $A_{2}\left(P_{2} A_{2}\right)$ activity regulates the overall output of prostaglandins, protein kinase $\mathrm{C}$ (PKC) activity determines the relation of $\mathrm{PGD}_{2}$ and $\mathrm{PGE}_{2}$ formation; up-regulation of PKC by a short-term $(2 \mathrm{~h})$ exposure of Kupffer cells to phorbol ester decreases, downregulation by $24 \mathrm{~h}$ exposure to phorbol 12-myristate 13-acetate (PMA) increases the $\mathrm{PGE}_{2} / \mathrm{PGD}_{2}$ ratio $^{23}$ (Fig 3).

$\mathrm{PGE}_{2}$ rather than $\mathrm{PGD}_{2}$ acts as a regulator of intrahepatic signalling. $\mathrm{PGE}_{2}$ suppresses the LPS-stimulated synthesis of TNF- $\alpha$ and IL-1 $\beta$ (but not of IL-6!) at the transcriptional level as shown by Northern blotting and reverse transcriptase-polymerase chain reaction ${ }^{24}$ (Fig 4); the suppressive effect of $\mathrm{PGE}_{2}$ becomes detectable about $30 \mathrm{~min}$ after LPS exposure and lasts for more than $36 \mathrm{~h}$.

cAMP, the production of which is enhanced by $\mathrm{PGE}_{2}$, appears to mediate $\mathrm{PGE}_{2}$-triggered gene expression. $\mathrm{PGE}_{2}$ also influences the formation of cytokine receptors on Kupffer cells and thus participates in regulated autocrine stimulation. Kupffer cells

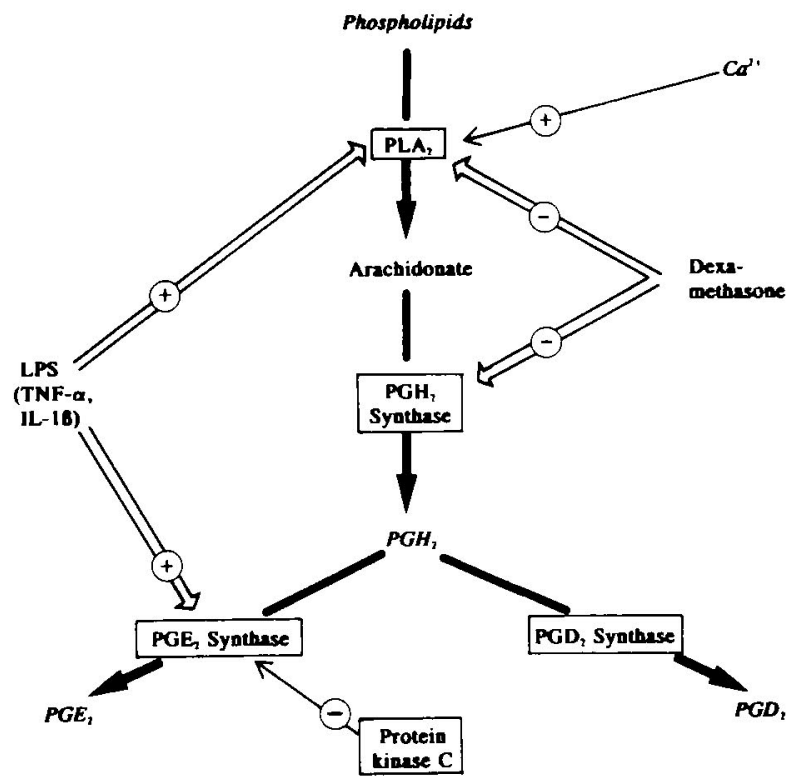

Pathway, ; activation/inbibition, $\bigcirc_{\downarrow}$; induction/repression,

Fig 3 Regulation of prostaglandin synthesis in rat kupffer cells. ${ }^{23}$ were found to express the IL-6 receptor (IL-6-R) constitutively. IL- 6 as well as various stimulators of IL-6 synthesis decreased the level of IL-6 receptor mRNA. However, $\mathrm{PGE}_{2}$ not only fails to inhibit IL-6 production, it actually enhances the level of IL-6-R mRNA and the number of IL-6-R molecules on the Kupffer cells surface ${ }^{25}$ thereby counteracting the suppression of receptor synthesis by LPS.

In the rat liver $\mathrm{PGE}_{2}$ attenuates pro-inflammatory signals and enhances antiinflammatory processes (Fig 5): It stimulates NO synthesis and counteracts the contraction of stellate cells thereby facilitating the flow of blood to the liver. The lack of inhibition of IL-6 synthesis by $\mathrm{PGE}_{2}$, in contrast to TNF- $\alpha$, allows the release of acute-phase reactants from the liver.

While no satisfactory evidence for a physiological role of $\mathrm{PGD}_{2}$ in the liver is yet available, $\mathrm{TxA}_{2}$ was found to be a potent effector of hepatic hemodynamics. The rise in portal pressure following in situ stimulation of Kupffer cells is, to a large extent, suppressible by inhibitors of $\mathrm{TxA}_{2}$ synthesis or $\mathrm{TxA}_{2}$ receptor antagonists. ${ }^{26} \mathrm{TxA}_{2}$ synergizes with $\mathrm{PGF}_{2 \alpha}$ and endothelin-1 in bringing about the contraction of stellate cells. This effect is mediated by inositol trisphosphate and $\mathrm{Ca}^{2+}$ and antagonized by Iloprost, a prostacyclin ( $\mathrm{PGI}_{2}$ ) analogue. ${ }^{14}$ Iloprost activates the adenylate cyclase of Kupffer cells. Contraction by $\operatorname{TxA}_{2}$ and relaxation by Iloprost are accompanied by the formation and disaggregation, respectively, of actin stress fibers.

Platelet-activating factor (PAF) has been shown to play an important role in the generation of TNF- $\alpha$ and superoxide in guinea pig peritoneal macrophages. Liver

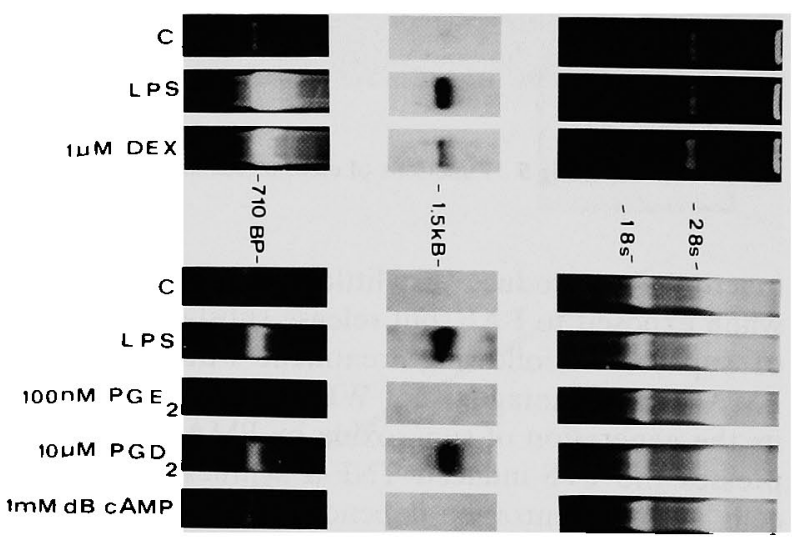

Fig 4 Differential effects of $\mathrm{PGE}_{2}$ and dexamethasone on LPSelicited TNF- $\alpha$ mRNA synthesis. Upper panel, total RNA; middle panel, northem blot with a biotin-labelled, TNF- $\alpha$-specific antisense RNA probe; lower panel, ethidium bromide stain of the DNA obtained after reverse transcription of RNA sample by polymerase chain reaction using TNF- $a$-specific primers. ${ }^{24}$ 


\section{Intrahepatic Effects of Prostaglandins}

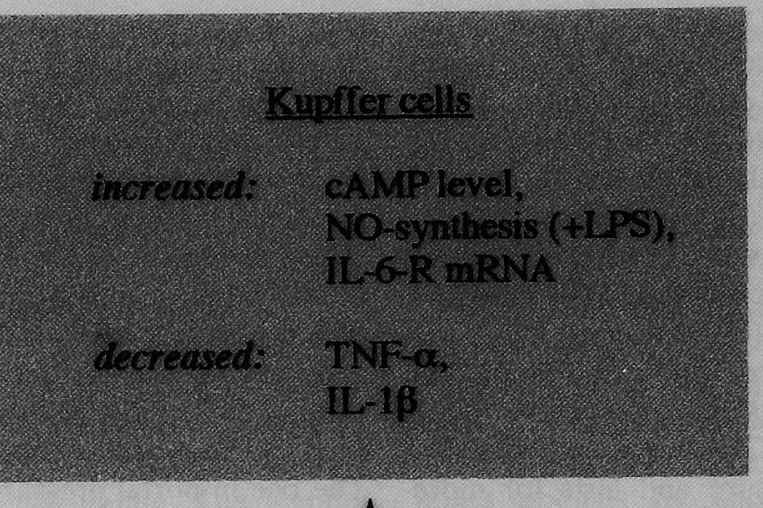

\section{Stellate cells}

increased:

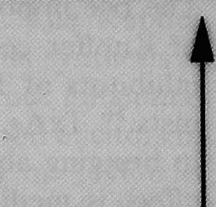

\section{relaxation}

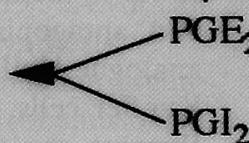

PGE

Ins: $P_{3}$

$\mathrm{Ca}_{i}^{2+}$ contraction

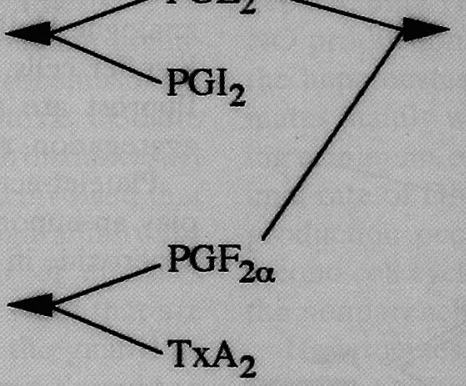

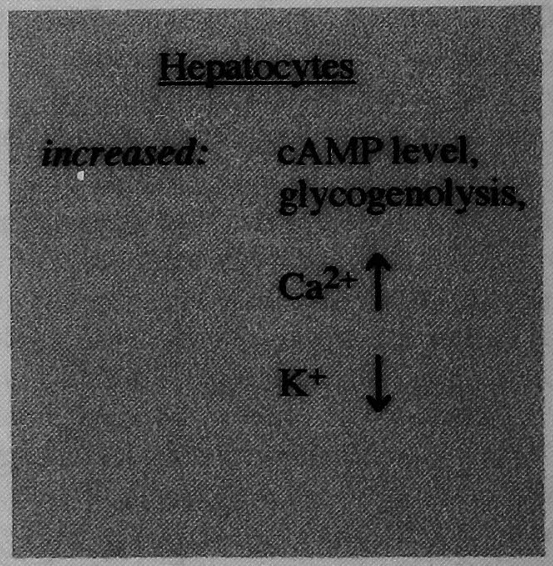

Fig 5 Functions of eicosanoids in the rat liver. IL-6R, interleukin-6 receptor; $\operatorname{InsP}_{3}$, inositol trisphosphate.

macrophages produce very little TNF- $\alpha$ and superoxide when exposed to PAF, but release substantial amounts of superoxide following treatment with zymosan or PMA. A PAF antagonist, ${ }^{27}$ WEB 2170 , not only inhibits the generation of superoxide by PMA but also suppresses the LPS-induced TNF- $\alpha$ synthesis by Kupffer cells in a concentration-dependent manner. According to a Northern blot analysis, the expression of TNF- $\alpha$ mRNA induced by LPS in Kupffer cells is partially abrogated by PAF antagonists. Furthermore, WEB 2170 reduces the PMA-induced leakage of lactate dehydrogenase from Kupffer cells in a dose-dependent manner. Evidently, TNF- $\alpha$ and superoxide syntheses in Kupffer cells are rather insensitive to exogenous PAF, while PAF antagonists interfere with the transduction of signals from LPS, PMA or zymosan. It may be that a PAF receptor located intracellularly rather than at the plasma membrane is involved in the inflammatory response of rat Kupffer cells.

\section{Regulation of Mediator Synthesis and Action in the Liver}

Several mediators produced by sinusoidal liver cells interact to establish a self-regulatory system. In view of the intricate interactions of these mediators, the regulation of their synthesis, degradation and action is of particular importance. A phenomenon mostly seen 
with unicellular components of the reticulo-endothelial system is autostimulation. The term "autacoids" is frequently used for such autocrine processes. This positive feedback loop consists of an inducible machinery for the generation of a mediator, its release from the cell and a receptor for this mediator on the same cell. In most instances it can be shown that the mediator has to pass through the extracellular space. A regulatory circuit employing different mediators operates in macrophages (Fig 6). LPS-exposed Kupffer cells synthesize TNF- $\alpha$ that, in turn, elicits $\mathrm{PGE}_{2}$ release by the same macrophages. ${ }^{28}$ This PG, however, is at the same time an efficient inhibitor of TNF- $\alpha$ and IL- $1 \beta$ synthesis at the transcriptional level. ${ }^{24}$ Moreover, it is an enhancer of its own, TNF- $\alpha$-provoked formation. Thus, one observes in these cells after LPS stimulation a rather rapid though transient synthesis of TNF- $\alpha$. On the other hand, $\mathrm{PGE}_{2}$ synthesis begins slowly but continues steadily for a long period of time. ${ }^{29}$ In addition, the eicosanoid influences the expression of TNF-receptor-1.

A network of different mediators and cell types participates in the pathological sequelae following an inflammatory insult of the liver (Fig 7). In mice, TNF- $\alpha$ was shown to bind strongly to the surface - probably to receptors - of endothelial cells. ${ }^{30}$ In this form it is able to induce granulocytes to stick to the endothelium

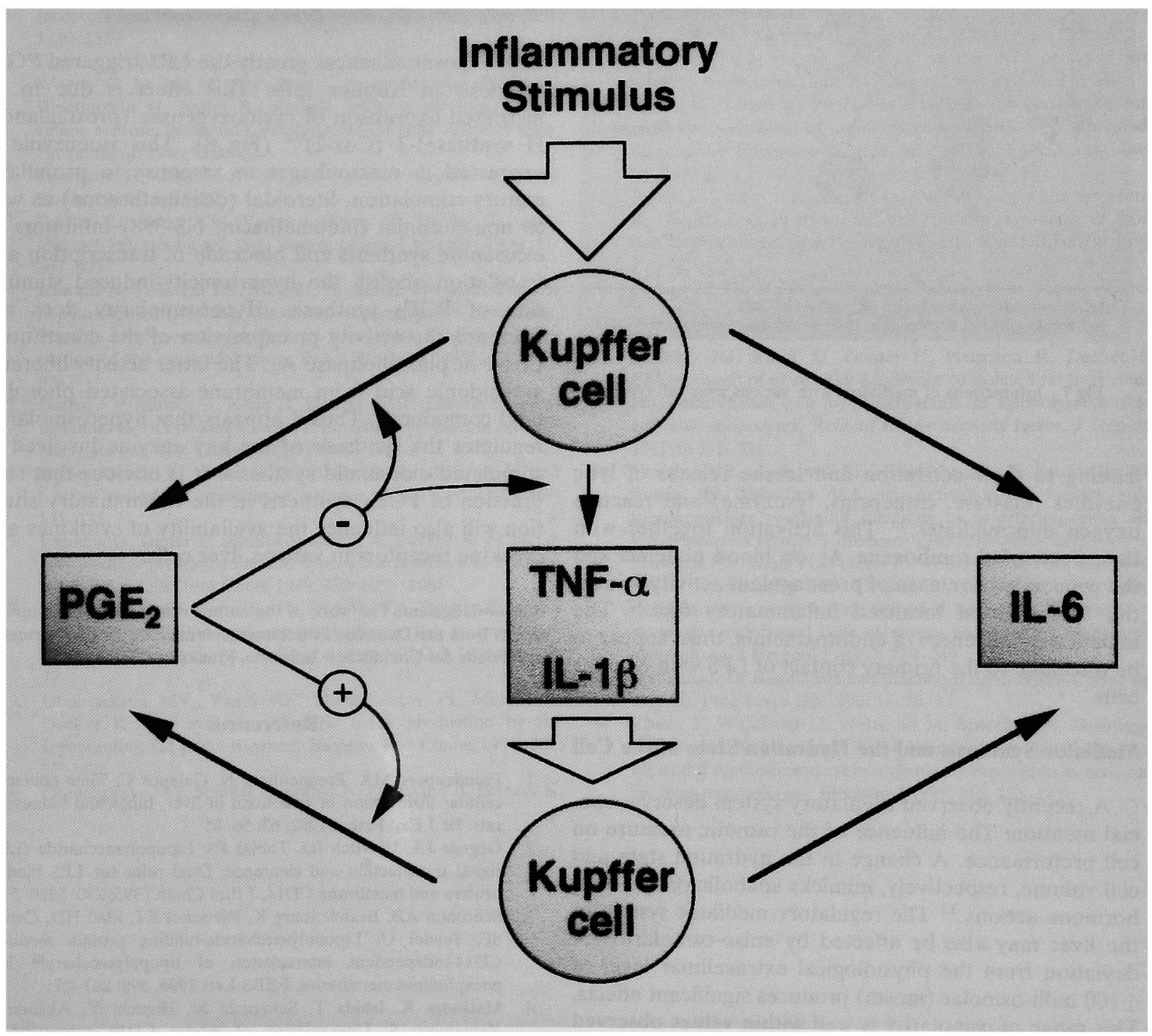

Fig 6 Regulatory loop of cytokines and prostaglandin $E_{2}$ in rat kupffer cells. 


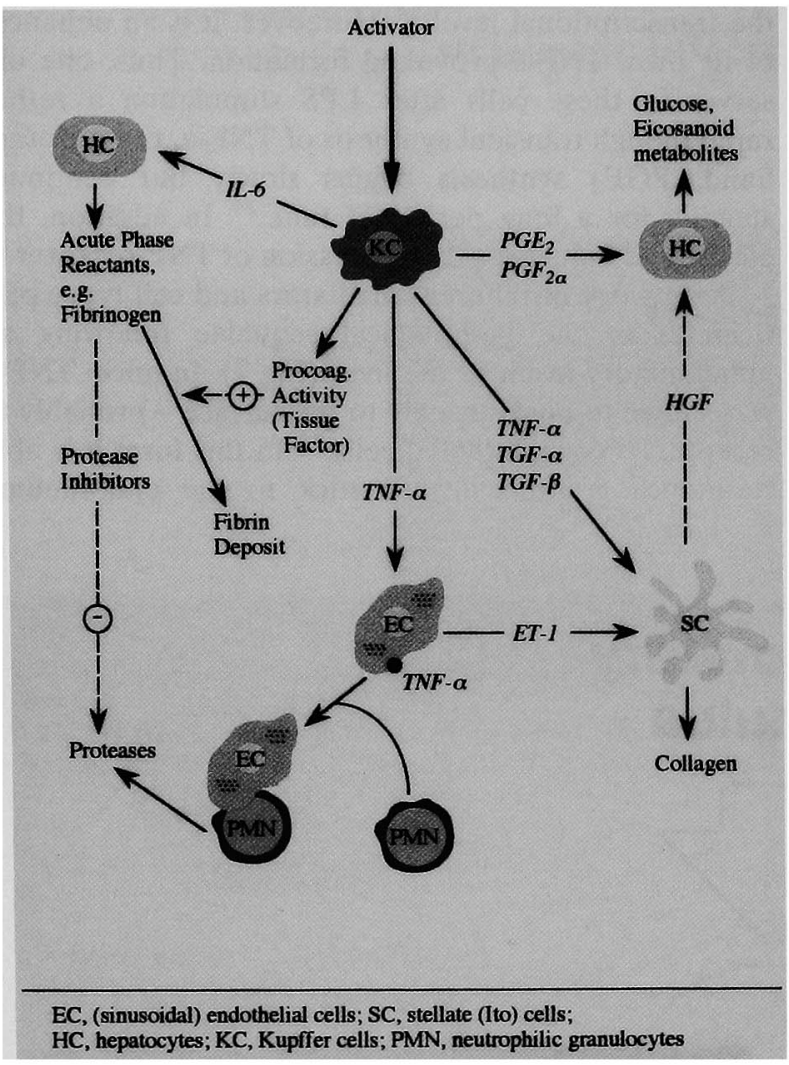

Fig 7 Interactions of mediators with various liver cell types.

leading to their activation and to the release of lytic enzymes (elastase, cathepsins, lysozyme) and reactive oxygen intermediates. ${ }^{31}$ This activation together with the effects of thromboxane $A_{2}$ on blood platelets and the concomitant release of procoagulant activity initiate the formation of localized inflammatory foci. ${ }^{32}$ The hepatic consequences of endotoxinemia, thus, appear to be traceable to the primary contact of LPS with Kupffer cells.

\section{Mediator Synthesis and the Hydration State of the Cell}

A recently observed regulatory system deserves special mention: The influence of the osmotic pressure on cell preformance. A change in the hydration state and cell volume, respectively, mimicks anabolic or catabolic hormone actions. ${ }^{33}$ The regulatory mediator system of the liver may also be affected by aniso-osmolarity. A deviation from the physiological extracellular level of \pm 100 milli-osmolar (mosm) produces significant effects. This range of osmolarity is well within values observed in vivo.

An increase of the extracellular osmolarity from 305

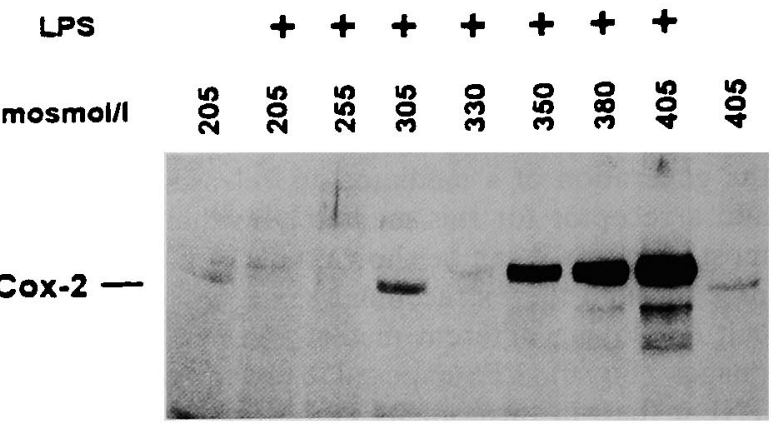

Fig 8 Induction of cyclooxygenase-2 (Cox-2) by LPS and hyperosmolarity. The effects of different osmolarities of the medium are shown. ${ }^{34}$

to 405 mosm enhances greatly the LPS-triggered $\mathrm{PGE}_{2}$ synthesis in Kupffer cells. This effect is due to an increased expression of cyclooxygenase (prostaglandin $\mathrm{H}$ synthase)-2 (Cox-2) ${ }^{34}$ (Fig 8). This isoenzyme is expressed in macrophages in response to proinflammatory stimulation. Steroidal (dexamethasone) as well as non-steroidal (indomethacin, NS-398) inhibitors of eicosanoid synthesis and blockade of transcription and translation abolish the hypertonicity-induced stimulation of $\mathrm{PGE}_{2}$ synthesis. Hyperosmolarity does not influence the activity or expression of the constitutive Cox-1 or phospholipase $A_{2}$. The latter activity liberates arachidonic acid from membrane-associated phosphatidyl compounds. Thus it appears that hyperosmolarity regulates the synthesis of the key enzyme involved in stimulated eicosanoid synthesis. It is obvious that suppression of $\mathrm{PGE}_{2}$ synthesis in the inflammatory situation will also influence the availability of cytokines and cytokine receptors in various liver cells.

Acknowledgment: The work of the author was supported by several grants from the Deutsche Forschungsgemeinschaft, Bonn (Germany) and Fonds der Chemischen Industrie, Frankfurt (Germany).

\section{References}

1. Freudenberg MA, Freudenberg N, Galanos C: Time course of cellular distribution of endotoxin in liver, lungs and kidneys of rats. Br J Exp Pathol 1982; 63: 56-65

2. Gegner JA, Ulevitch RJ, Tobias PS: Lipopolysaccharide (LPS) signal transduction and clearance. Dual roles for LPS binding protein and membrane CD14. J Biol Chem 1995; 270: 5320-5325

3. Schromm AB, Brandenburg K, Rietschel ET, Flad HD, Carroll SF, Seydel U: Lipopolysaccharide-binding protein mediates CD14-independent intercalation of lipopolysaccharide into phospholipid membranes. FEBS Lett 1996; 399: 267-271

4. Matsuura K, Ishida T, Setoguchi M, Higuchi $Y$, Akizuki S, Yamamoto S: Upregulation of mouse CD14 expression in Kupffer cells by lipopolysaccharide. J Exp Med 1994; 179: 16711676 
5. Baeuerle PA, Baltimore D: The physiology of NFKB transcription factor. In: Cohen P, Foulkes JG, eds, Molecular Aspects of Cellular Regulation, Vol. 6, Amsterdam, Elsevier, $1991 ; 409-432$

6. Baeuerle PA, Baltimore D: IkB: a specific inhibitor of the NFkB transcription factor. Science 1988; 242: 540-546

7. Müller JM, Ziegler-Heitbrock HW, Baeuerle PA: Nuclear factor $\mathrm{KB}$, a mediator of lipopolysaccharide effects. Immunobiology 1993; 187: 233-256

8. Ziegler-Heitbrock HW, Sternsdorf T, Liese J, Belohradsky B, Weber C, Wedel A, Schreck R, Baeuerle P, Ströbel M: Pyrrolidine dithiocarbamate inhibits NF-kB mobilisation and TNF production in human monocytes. J Immunol 1993; 151: 6986-6993

9. Tran-Thi TA, Decker K, Baeuerle PA: Differential activation of transcription factors NF-kB and AP-1 in rat liver macrophages. Hepatology 1995; 22: 613-619

10. Ertel W, Scholl FA, Gallati H, Bonaccio M, Schildberg FW, Trentz $O$ : Increased release of soluble tumor necrosis factor receptors into blood during clinical sepsis. Arch Surg 1994; 129: 1330-1337

11. Eugster HP, Müller M, Karrer U, Car BD, Schnyder B, Eng VM, Woerly G, Le Hir M, di Padova F, Aguet M, Zinkernagel R, Bluethmann H, Ryffel B: Multiple immune abnormalities in tumor necrosis factor and lymphotoxin $\alpha$ double-deficient mice. Int Immunol 1996; 8: 23-36

12. Baumann $\mathbf{H}$, Gauldie J: The acute phase response. Immunol Today $1994 ; 15: 74-80$

13. Busam KJ, Bauer TM, Bauer J, Gerok W, Decker K: Interleukin- 6 release by rat liver macrophages. J Hepatol 1990; 11: 367-373

14. Kawada N, Tran-Thi TA, Klein H, Decker K: The contraction of hepatic stellate (Ito) cells stimulated with vasoactive substances. Possible involvement of endothelin 1 and nitric oxide in the regulation of the sinusoidal tonus. Eur J Biochem 1993; 213: 815823

15. Gaillard T, Mülsch A, Klein H, Decker K. Regulation by prostaglandin $E_{2}$ of cytokine-elicited nitric oxide synthesis in rat liver macrophages. Biol Chem 1992; 373: 897-902

16. Darley-Usmar V, Wiseman $H$, Halliwell $B$ : Nitric oxide and oxygen radicals: a question of balance. FEBS Lett 1995; 369: 131-135

17. Latocha G, Dieter P, Schulze-Specking A, Decker K: Fc receptors mediate prostaglandin and superoxide synthesis in cultured rat Kupffer cells. Biol Chem 1989; 370: 1055-1061

18. Obolenskaya MY, Bernauer H, Tran-Thi TA, Decker K: Levels of RNA for TNF- $\alpha$ and receptors during the prereplicative period of liver regeneration. Biopolymers and Cell 1994; 10: 68 77

19. Obolenskaya MY, Vanin AF, Mordvintecev PI, Mülsch A, Decker K: Epr evidence of nitric oxide production by the regenerating rat liver. Biochem Biophys Res Comm 1994; 202: $571-576$

20. Obolenskaya MY, Schulze-Specking A, Plaumann B, Frenzer K,
Freudenberg N, Decker K: Nitric oxide production by cells isolated from regenerating rat liver. Biochem Biophys Res Comm 1994; 204: 1305-1311

21. Tran-Thi TA, Gyufko K, Decker K: Fate of exogenous and endogenous prostaglandin $\mathrm{D} 2$ and $\mathrm{E} 2$ in the perfused rat liver. Eicosanoids 1991; 4: 37-46

22. Decker K: Biologically active products of stimulated liver macrophages (Kupffer cells). Eur J Biochem 1990; 192: 245-261

23. Grewe M, Duyster J, Dieter P, Henninger H, Schulze-Speaking $A$, Decker $K$ : Prostaglandin $D_{2}$ and $E_{2}$ syntheses in rat Kupfer cells are antagonistically regulated by lipopolysaccharide and phorbol ester. Biol Chem 1992; 373: 655-664

24. Grewe M, Gausling R, Gyufko K, Hoffmann R, Decker K: Regulation of mRNA expression for tumor necrosis factor- $\alpha$ in rat liver macrophages. J Hepatol 1994; 20: 811-818

25. Hoffmann R, Henninger HP, Schulze-Specking A, Decker K: Regulation of interleukin-6 receptor expression in rat Kupffer cells: modulation by cytokines, dexamethasone and prostaglandin $E_{2}$. J Hepatol 1994; 21: 543-550

26. Tran-Thi TA, Gyufko K, Reinke M, Decker K: Output and effects of thromboxane produced by the liver perfused with phorbol myristate acetate. Biol Chem 1988; 369: 1179-1184

27. Zhang F, Decker K: Platelet-activating factor antagonists suppress the generation of tumor necrosis factor- $\alpha$ and superoxide induced by lipopolysaccharide or phorbol ester in rat liver macrophages. Eur Cytokine Netw 1994; 5: 311-317

28. Peters $T$, Karck U, Decker K: Interdependence of tumor necrosis factor, prostaglandin E2 and protein synthesis in lipopolysaccharide-exposed rat Kupffer cells. Eur J Biochem 1990; 191: 583-589

29. Busam KJ, Homfeld A, Zawatzky R, Kästner S, Bauer J, Gerok W, Decker K: Virus- versus endotoxin-induced activation of liver macrophages. Eur J Biochem 1990; 191: 577-582

30. Schlayer HJ, Karck U, Ganter U, Hermann R, Decker K: Enhancement of neutrophil adherence to isolated rat liver sinusoidal endothelial cells by supernatants of lipopolysaccharideactivated monocytes. Role of tumor necrosis factor. J Hepatol 1987; 5: $311-321$

31. Shalaby MR, Aggarwal BB, Rinderknecht E, Svedersky LP, Finkle BS, Palladino MA Jr: Activation of human polymorphonuclear neutrophil functions by interferongamma and tumor necrosis factors. J Immunol 1985; 135: 2069-2073

32. Schlayer HJ, Laaff H, Peters T, Woort-Menker M, Estler C, Karck U, Schaefer HE, Decker K: Involvement of tumor necrosis factor in endotoxin-triggered neutrophil adherance to sinusoidal endothelial cells of mouse liver and its modulation acute phase. J Hepatol 1988; 7: 239-249

33. Häussinger $D$ : Regulation and functional significance of liver cell volume. Prog Liver Dis 1996; 14: 29-53

34. Zhang F, Warskulat U, Wettstein M, Schreiber R, Henninger HP, Decker K, Häussinger D: Hyperosmolarity stimulates prostaglandin synthesis and cyclooxygenase- 2 expression in activated rat liver macrophages. Biochem J 1995; 312: 135-143 